\title{
Chapter 6 \\ Overview of Engineering Mathematics Education for STEM in EU
}

\subsection{Engineering Mathematics Education in Finland}

\section{Tuomas Myllykoski and Seppo Pohjolainen (ه)}

Tampere University of Technology (TUT), Laboratory of Mathematics, Tampere, Finland

e-mail: tuomas.myllykoski@tut.fi; seppo.pohjolainen@tut.fi

The Finnish higher education system consists of two complementary sectors: polytechnics and universities. The mission of universities is to conduct scientific research and provide undergraduate and postgraduate education based on it. Polytechnics train professionals in response to labor market needs and conduct R\&D which supports instruction and promotes regional development in particular.

Universities promote free research and scientific and artistic education, provide higher education based on research, and educate students to serve their country and humanity. In carrying out this mission, universities must interact with the surrounding society and strengthen the impact of research findings and artistic activities on society.

Under the new Universities Act, which was passed by Parliament in June 2009, Finnish universities are independent corporations under public law or foundations under private law (Foundations Act). The universities have operated in their new form from 1 January 2010 onwards. Their operation is built on the freedom of education and research and university autonomy.

Universities confer Bachelor's and Master's degrees, and postgraduate Licentiate and Doctoral degrees. Universities work in cooperation with the surrounding society and promote the social impact of research findings. The higher education 
system, which comprises universities and polytechnics, is being developed as an internationally competitive entity capable of responding flexibly to national and regional needs. There are technological universities in Helsinki, Tampere and Lappeenranta, and technological faculties in Oulu, Vaasa and Turku. Approximately 4000-5000 students begin their studies in one of these universities annually. The Finnish education system diagram is in Fig. 6.1.

The system of polytechnics is still fairly new. The first polytechnics started to operate on a trial basis in the beginning of 1990s and the first was made permanent in 1996. By 2000 all polytechnics were working on a permanent basis. Polytechnics are multi-field regional institutions focusing on contacts with working life and on regional development. The total number of young and mature polytechnic students is 130,000 . Polytechnics award over 20,000 polytechnic degrees and 200 polytechnic Master's degrees annually. The system of higher degrees was put in place after a trial period in 2005 and the number of polytechnic Master's programs is expected to grow in the coming years.

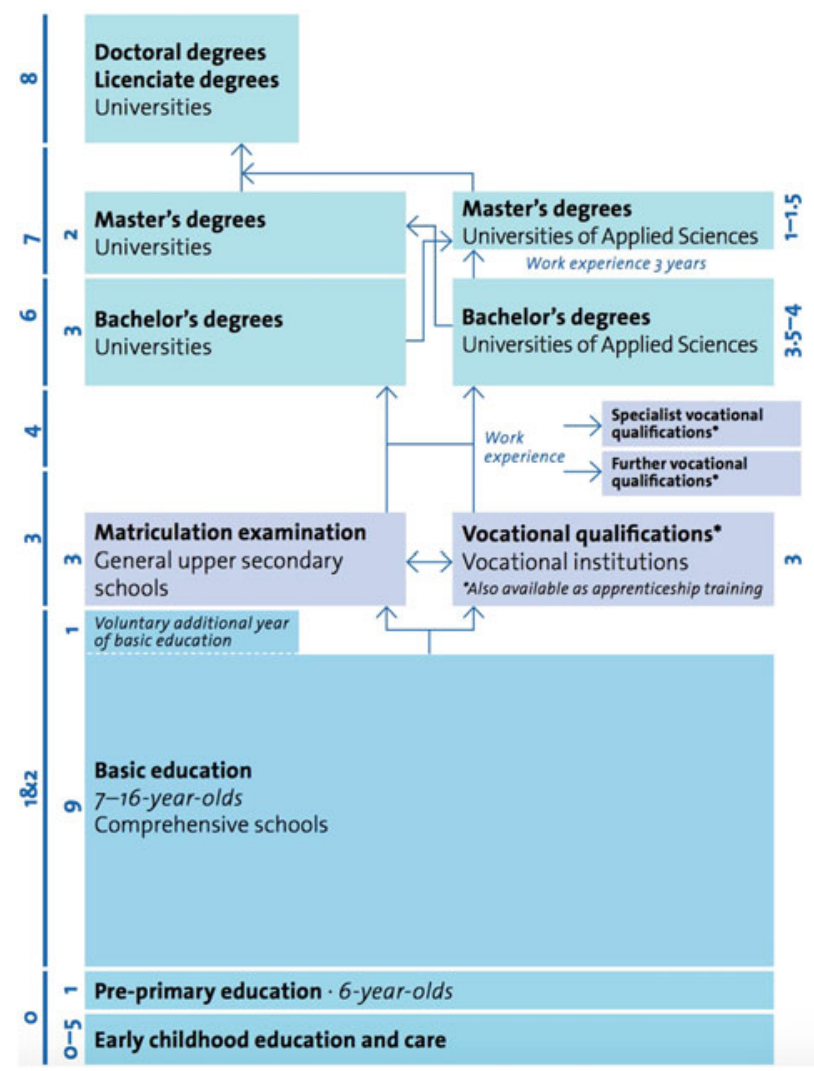

Fig. 6.1 The Finnish education system (http://www.oph.fi/english/education_system) 


\subsubsection{Tampere University of Technology}

Tampere University of Technology (TUT) is Finland's second-largest university in engineering sciences. TUT conducts research in the fields of technology and architecture and provides higher education based on this research. TUT is located in Tampere, the Nordic countries' largest inland city, some $170 \mathrm{~km}$ north of the capital Helsinki. TUT's campus in the suburb of Hervanta is a community of 10,500 undergraduate and postgraduate students and close to 2000 employees. Internationality it is an inherent part of all the University's activities. Around 1500 foreign nationals from more than 60 countries work or pursue studies at TUT.

TUT offers its students an opportunity for a broad, cross-disciplinary education. Competent Masters of Science of Technology and Architecture as well as Doctors of Technology and Philosophy graduated from TUT are in high demand among employers.

The University combines a strong tradition of research in the fields of natural sciences and engineering with research related to industry and business. Technology is the key to addressing global challenges. The University's leading-edge fields of research are signal processing, optics and photonics, intelligent machines, biomodeling and the built environment.

TUT generates research knowledge and competence for the benefit of society. The University is a sought-after partner for collaborative research and development projects with business and industry and a fertile breeding ground for innovation and new research- and knowledge-based companies.

In 2013 the total funding of TUT Foundation, which operates as Tampere University of Technology, was 157.6 million euros. Close to $50 \%$ of the University's funding was external funding, such as revenue from The Finnish Funding Agency for Technology and Innovation (Tekes), industry, the Academy of Finland and EU projects.

TUT started operating in the form of a foundation in the beginning of 2010. The independence of a foundation university and the proceeds of the 137 million euro foundation capital further promote the development of research and education at TUT.

\subsubsection{Overview of Mathematics Education at TUT}

The Department of Mathematics is responsible for teaching core mathematics to all engineering students at Tampere University of Technology, and it offers courses and degree programs at the Bachelor's, Master's, and Postgraduate level for studies in mathematics. The faculty of the department conducts research in mathematics and its applications at an internationally competitive level. 
The Department of Mathematics offers mathematics and statistics expertise for research and development projects in the private and public sectors. Research services and collaboration can range from informal working relationships to shorteror longer-term research contracts.

The teaching of mathematics for the following degree programs is the responsibility of the Department of Mathematics on the Bachelor and Master level:

- Automation Engineering

- Biotechnology

- Civil Engineering

- Signal Processing and Communications Engineering

- Electrical Engineering

- Environmental and Energy Technology

- Industrial Engineering and Management

- Information and Knowledge Management

- Information Technology

- Materials Engineering

- Mechanical Engineering

- Science and Engineering

Generally, the mandatory amount of mathematics is 27 ECTS in the Bachelor's degree. The mandatory mathematics consists of Engineering Mathematics 1-3 courses (altogether 15 ECTS) (Table 6.1), studied during the first year, and three elective courses 4 ECTS each on the first and second year (Table 6.2). The degree program makes the recommendation on the elective courses suitable for their students. The degree program can place one or two mandatory mathematics courses in their Master's program. Then these courses are not part of the BSc program but belong to the MSc program. The degree programs may recommend students to include additional mathematics courses in their study plan. In this case the amount of mathematics exceeds 27 ECTS.

Table 6.1 Mandatory engineering mathematics courses at TUT

\begin{tabular}{l|l|l|l}
\hline Course & ECTS & Year & Contents \\
\hline $\begin{array}{l}\text { Engineering } \\
\text { Mathematics 1 (EM1) }\end{array}$ & 5 & 1 & $\begin{array}{l}\text { Set theory and mathematical logic; real functions; } \\
\text { elementary functions; limits; derivative; complex } \\
\text { numbers; zeros of polynomials }\end{array}$ \\
\hline $\begin{array}{l}\text { Engineering } \\
\text { Mathematics 2 (EM2) }\end{array}$ & 5 & 1 & $\begin{array}{l}\text { Vectors in } \mathbb{R}^{n} \text { spaces; linear equations, Gauss' } \\
\text { elimination; vector spaces; matrices, } \\
\text { eigenvectors, determinants; orthogonality }\end{array}$ \\
\hline $\begin{array}{l}\text { Engineering } \\
\text { Mathematics 3 (EM3) }\end{array}$ & 5 & 1 & $\begin{array}{l}\text { Indefinite and definite integral; first and second } \\
\text { order differential equations; sequences; series }\end{array}$ \\
\hline
\end{tabular}


Table 6.2 Elective engineering mathematics courses at TUT

\begin{tabular}{l|l|l|l}
\hline Course & ECTS & Year & Contents \\
\hline $\begin{array}{l}\text { Engineering } \\
\text { Mathematics 4 (EM1) }\end{array}$ & 4 & 1 & $\begin{array}{l}\text { Multivariable functions,limit, continuity,partial } \\
\text { derivatives, gradient; vector valued functions, } \\
\text { matrix derivative, chain rule; maxima, minima, } \\
\text { Lagrange's method; plane and space integrals }\end{array}$ \\
\hline $\begin{array}{l}\text { Algorithm Mathematics } \\
\text { (AM) }\end{array}$ & 4 & 2 & $\begin{array}{l}\text { Set theory, methods of proofs; relations and } \\
\text { functions; propositional and predicative logic; } \\
\text { induction and recursion; Boolean algebra }\end{array}$ \\
\hline $\begin{array}{l}\text { Discrete Mathematics } \\
\text { (DM) }\end{array}$ & 4 & 1,2 & $\begin{array}{l}\text { Step-, impulse-, floor-, ceiling- signum functions; } \\
\text { Z-transform, difference equations; number } \\
\text { theory; graph theory }\end{array}$ \\
\hline Fourier Methods (FM) & 4 & 2 & $\begin{array}{l}\text { Real Fourier series; linearity, derivation; complex } \\
\text { Fourier series; discrete Fourier transform }\end{array}$ \\
\hline $\begin{array}{l}\text { Operational Research } \\
\text { (OA) }\end{array}$ & 4 & 2 & $\begin{array}{l}\text { Linear optimization; Simplex-method, sensitivity; } \\
\text { dual problem; transport model with applications; } \\
\text { warehouse models; game theory }\end{array}$ \\
\hline $\begin{array}{l}\text { Probability Calculus } \\
\text { (PC) }\end{array}$ & 4 & 2 & $\begin{array}{l}\text { Random variable and probability, Bayes' } \\
\text { formula; distributions and their parameters; joint } \\
\text { distributions, central limit theorem }\end{array}$ \\
\hline Statistics (MS) & 4 & 2 & $\begin{array}{l}\text { Descriptive statistics, samples; hypothesis testing, } \\
\text { parametric and nonparametric cases }\end{array}$ \\
\hline Vector Analysis (VA) & 4 & 2 & $\begin{array}{l}\text { Gradient, divergence; line integrals; conservative } \\
\text { vector field; surfaces, area, surface integral, flux } \\
\text { and Gauss' theorem }\end{array}$ \\
\hline
\end{tabular}

The study program recommends the selection of (at least) three of these courses

\subsubsection{Major/Minor in Mathematics (BSc, MSc)}

In addition to the courses provided for all degree programs, the department also has a well-rounded group of students who study mathematics as their major. The courses provided for these students are often based on the research topics of the department, as this further develops the department's strategy.

The Department of Mathematics offers courses and degree programs at the Bachelor's, Master's, and at the Postgraduate level. Doctoral studies can be carried out in the main research areas of the department.

Currently there are two majors in the Master's program of Science and Engineering fully given in English: Mathematics with Applications and Theoretical Computer Science, both by the Department of Mathematics. These offer the uniquely useful combination of strong mathematical modeling and tools of logical and algorithmic analysis. There is also a minor subject in Mathematics. As per agreement, it may also be included in other international Master's programs at TUT. 
The optional focus areas in Mathematics with Applications are Analysis, Discrete Mathematics, and Mathematical and Semantic Modeling. The subject can also be chosen as an extended one.

The postgraduate studies program leads to the $\mathrm{PhD}$ degree or the degree of Doctor of Technology. Subjects of the postgraduate studies at the department usually follow the research topics of the research groups. There is a local graduate school, which can provide financial support for doctoral studies.

On the Bachelor level, the minor or major in mathematics consists of 25 ECTS in mathematics in addition to the 27 ECTS studied by all students. For the major, the students will also complete a Bachelor's thesis worth 8 ECTS. If the student chooses not to take mathematics as a major, then they must complete an additional 10 ECTS of mathematics for a total of 60 ECTS. In the Master phase of studies, the students will complete either 30 or 50 ECTS of mathematics for their major, depending on their choice of minor studies. Those meaning to graduate from the Master's program with a major in mathematics are required to write the Master's thesis in mathematics that is worth 30 ECTS.

\subsubsection{Teacher Studies at TUT in Mathematics}

The students are offered the possibility of studying mathematics with the goal of attaining competency for teaching mathematics at Finnish schools. Students must study a minimum of 50 ECTS of mathematics in the university to be able to apply for the program. After applying, the students are evaluated by a board of academics at University of Tampere. Those who pass evaluation are given the possibility of studying at University of Tampere to obtain 60 ECTS of mandatory pedagogical studies. Students will study both at TUT and at the Tampereen Normaalikoulu-high school-where they work as real teachers with real students. The major in mathematics for teacher students is 120 ECTS, a minor is 60 ECTS of mathematics. Teacher students will also complete a 60 ECTS minor in pedagogical studies. Students have a possibility of studying multiple sciences in their teacher studies, with mathematics being accompanied by chemistry, physics and information technology. It is often suggested that students choose multiple sciences in order to further develop their possibilities in the future when looking for a job. The overall structure of teacher studies is depicted in Fig. 6.2. 


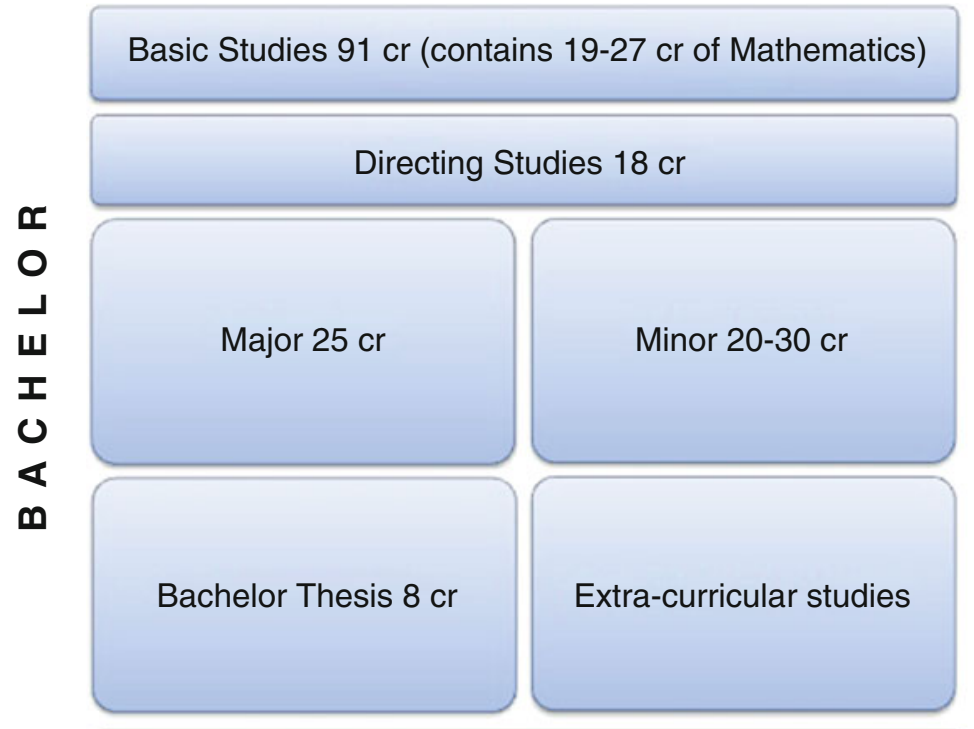

Common Program Core Studies (0-8 cr of mathematics)

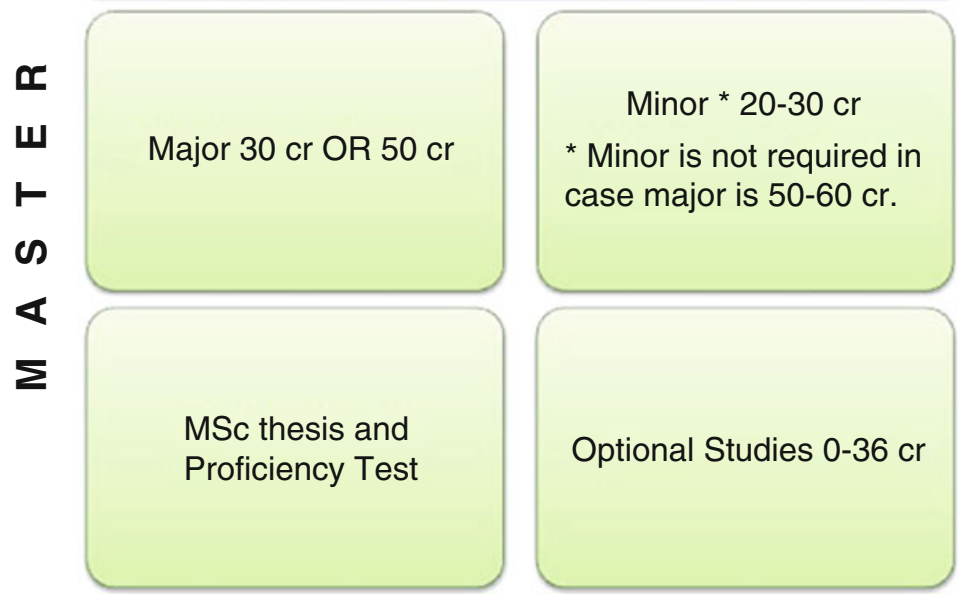

Fig. 6.2 Teacher studies in mathematics at TUT 


\subsection{Engineering Mathematics Education in France}

Christian Mercat and Mohamed El-Demerdash

IREM Lyon, Université Claude Bernard Lyon 1 (UCBL), Villeurbanne, France

e-mail: christian.mercat@math.univ-lyon1.fr

The Higher Education (HE) System in France training future engineers is organized not only around universities (the left half and the green vertical line in Fig. 6.3), but much more around Engineering Schools (blue line to the right) which have a special status. Pre-engineering schemes such as University Diploma of Technology (DUT) or usual Licence trainings are as well used as stepping stones for engineering degrees (16\% of engineers access their school with a DUT, $6 \%$ from a general academic scientific licence). The entrance selection scheme (represented by a red S bar in Fig. 6.3 is at the beginning of either the first year, right after Baccalaureate graduation, or the third year. A continuous selection weeds out failing students at the end of each year. Most of the data exploited in this chapter comes from Higher Education \& Research in France, facts and figures, 9th edition, November 2016, freely available for inspection on the following governmental website $^{1}$ :

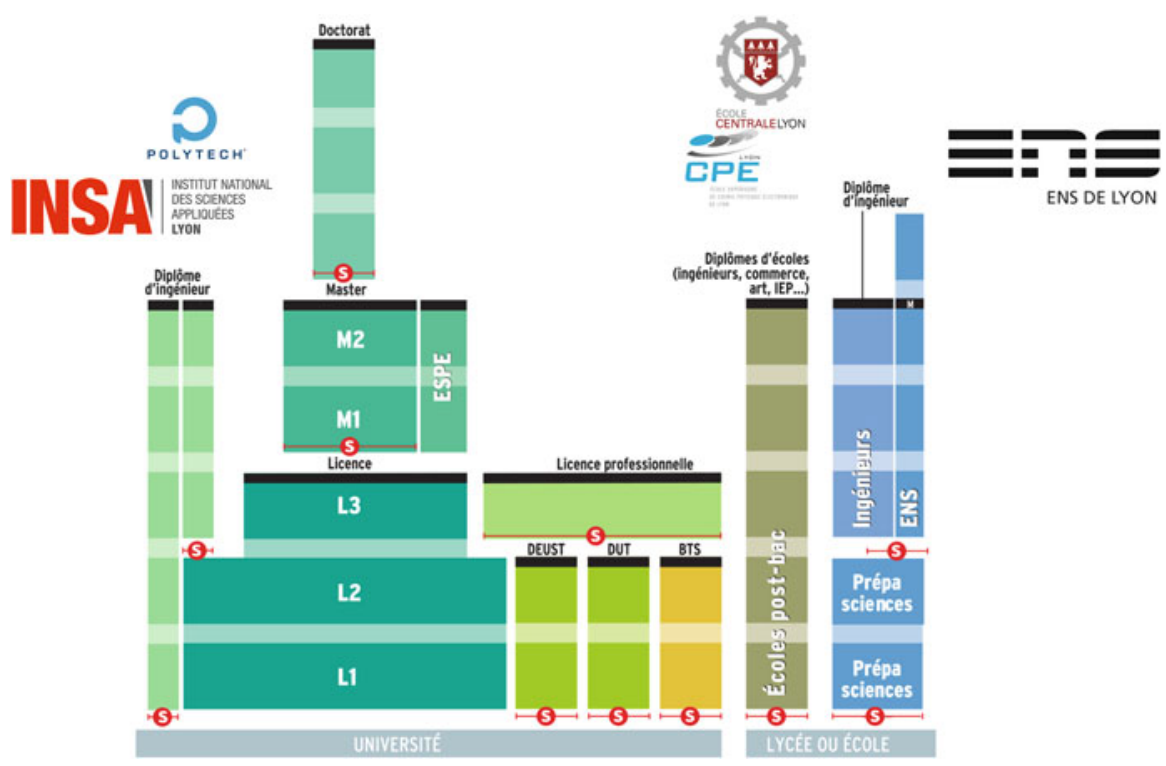

Fig. 6.3 French education system

\footnotetext{
${ }^{1}$ http://publication.enseignementsup-recherche.gouv.fr/eesr/9EN/.
} 


\subsubsection{Universities}

There are 73 universities in France, for a total of 1.5 million students, which represent $60 \%$ of the number of Higher Education students; see Fig. 6.4. The number of students has increased by a factor of 8 in the last 50 years to reach 2.5 million, the proportion of Baccalaureate holders increasing from a third in 1987 to twothirds of a generation in 1995 and three-quarters nowadays. The demographical increase is expected to make the numbers of HE students steadily grow in 10 years to reach 2.8 M. Short technician diplomas, BTS and DUT, are mainly responsible for this increase. These short technical diplomas follow the creation of vocational and technological Baccalaureates; see Fig. 6.5.

Whereas any European freshmen can enter French university (there is no entrance selection), a significant number of HE students will never go to university and it

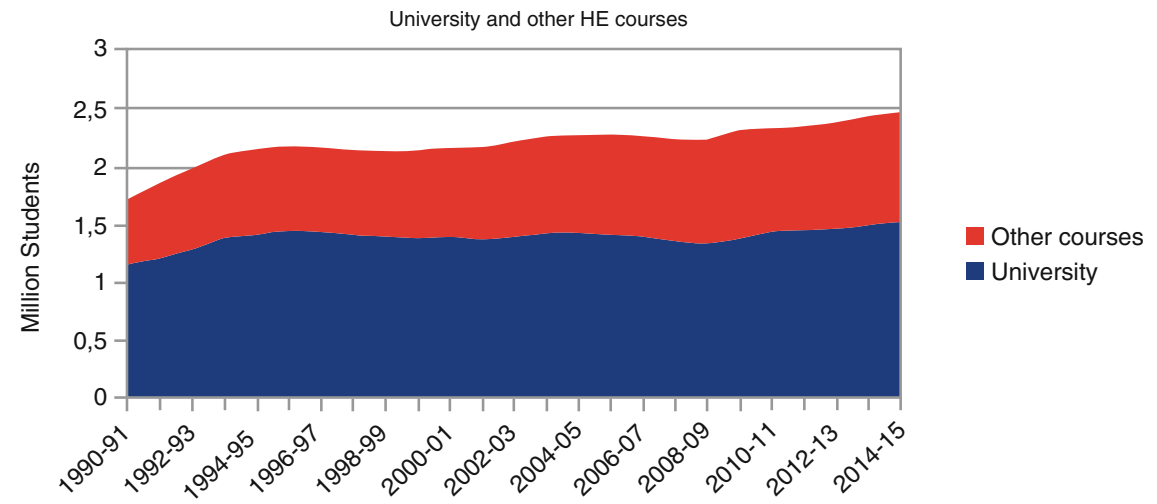

Fig. 6.4 The number of students in Higher Education

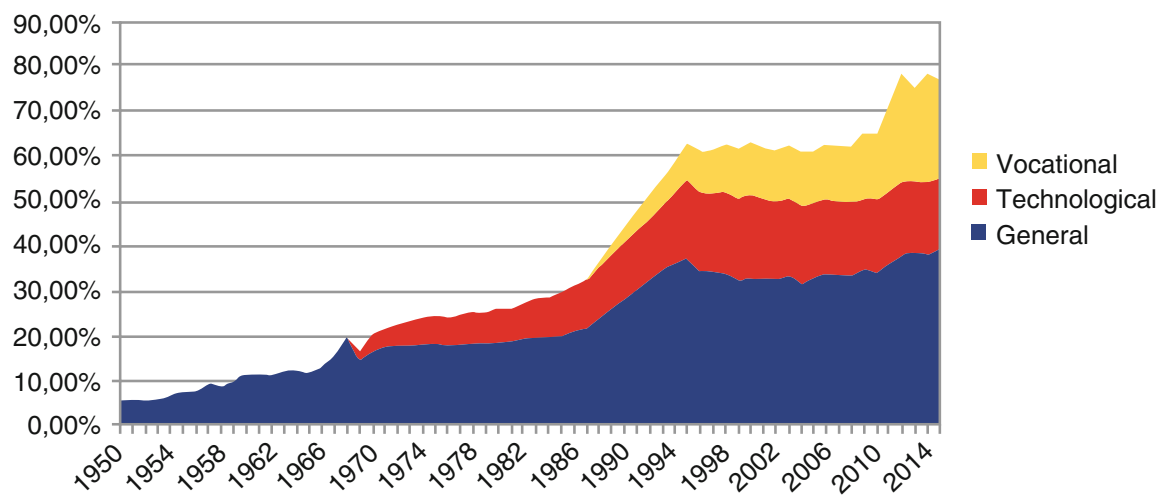

Fig. 6.5 Percent of a generation with Baccalaureate 
Fig. 6.6 Degrees per sector of Higher Education

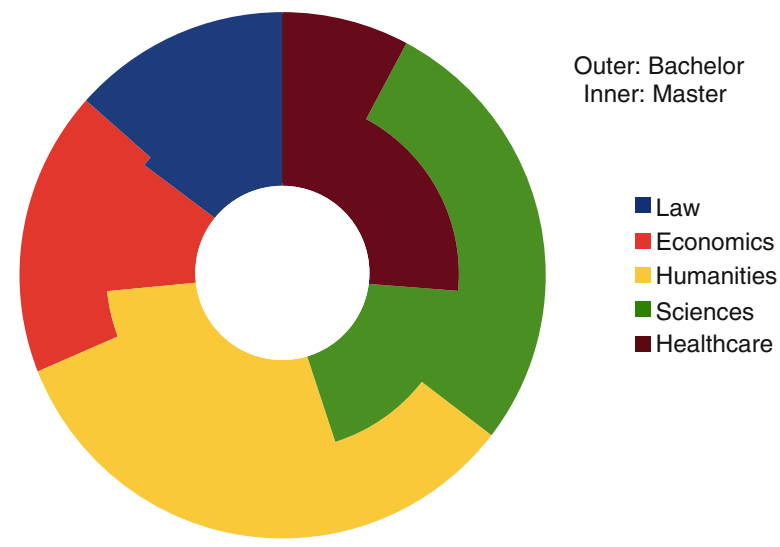

is especially true for engineers. There are around 63,000 permanent HE teachers in France, half of them in science and technology departments. Around 50,000 are researchers as well (a fixed half and half loads) and usually belong to a research institute accredited by one of the French Research Institute such as CNRS, INRIA or CEA. ${ }^{2}$ Around 13,000 permanent teachers are full time teachers and are not supposed to do research, their level is attested by the French Agrégation or equivalent. These Professeurs Agrégés (PRAG) are especially numerous in engineers schools. Around 24,000 teachers have non-permanent teaching positions. The curriculum is accredited by the ministry of higher education and research. These research institutes, as well as the programs and degrees delivered by universities are evaluated by an independent body, HCERES. ${ }^{3}$

The plot Fig. 6.6 of degrees per sector of higher education shows that, in proportion with other sectors, many more students leave Sciences with a simple Bachelor's degree and will not achieve a Master's degree. The reasons are twofold, a good and a bad one: first, a Bachelor's degree in science is sufficient to get a job compared to humanities or law for example, especially the BTS and DUT, and, second, science students are more likely to drop out earlier. Two-thirds of the scientific and technical Masters are in fact engineering degrees.

While the number of engineer's degrees has slightly increased, the lower preengineering degrees of Higher Technician Diploma (BTS) and University Diploma of Technology (DUT) have increased much more, following, respectively, the vocational and technological Baccalaureates; see Fig. 6.7.

Foreign students account for about $15 \%$ of the university students (DUT included) with a sharp increase in the first years of this century, from $8 \%$ in 2000. Some courses, such as preparatory schools (CPGE) and Technical University

\footnotetext{
${ }^{2}$ National Center for Scientific Research http://www.cnrs.fr/; National Institute for computer science and applied mathematics http://www.inria.fr; French Alternative Energies and Atomic Energy Commission http://www.cea.fr.

${ }^{3}$ High Council for Evaluation and Research and Higher Education, http://www.hceres.fr/.
} 


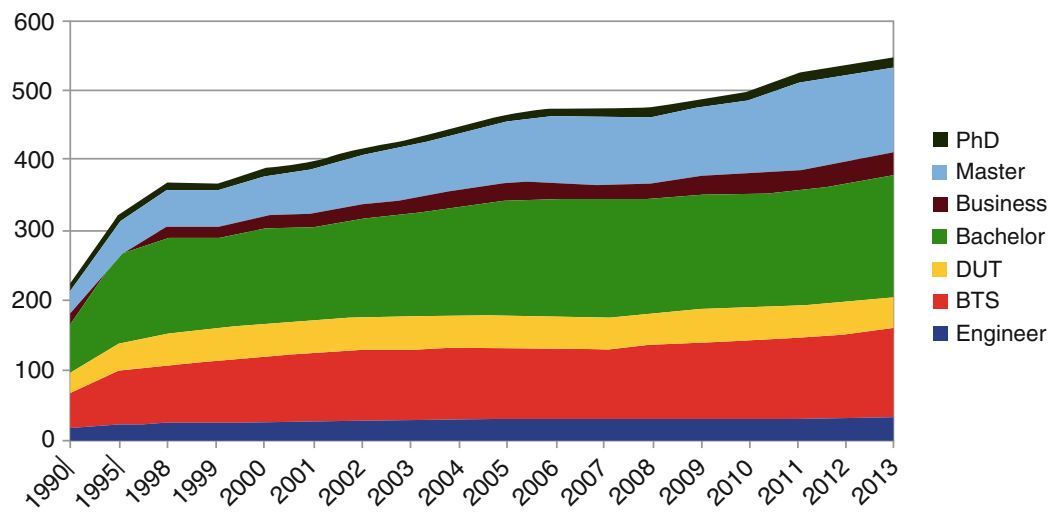

Fig. 6.7 Numbers of degrees (in thousands)

Diplomas (DUT), having no foreign counterparts, do not attract foreign students although they are competitive and channel a lot of engineers in France, especially the top engineering schools which have de facto mainly French students. Parallel admission systems allow for the inclusion of foreign students. It is especially the case for foreign students already holding a Master's degree and training a specialization in a French engineering school; see Fig. 6.8.

These students come traditionally mainly from Africa, notably Morocco, Algeria, Tunisia and Senegal, but more and more from Asia, remarkably from China. Germany and Italy are the main European partners; see Fig. 6.9.

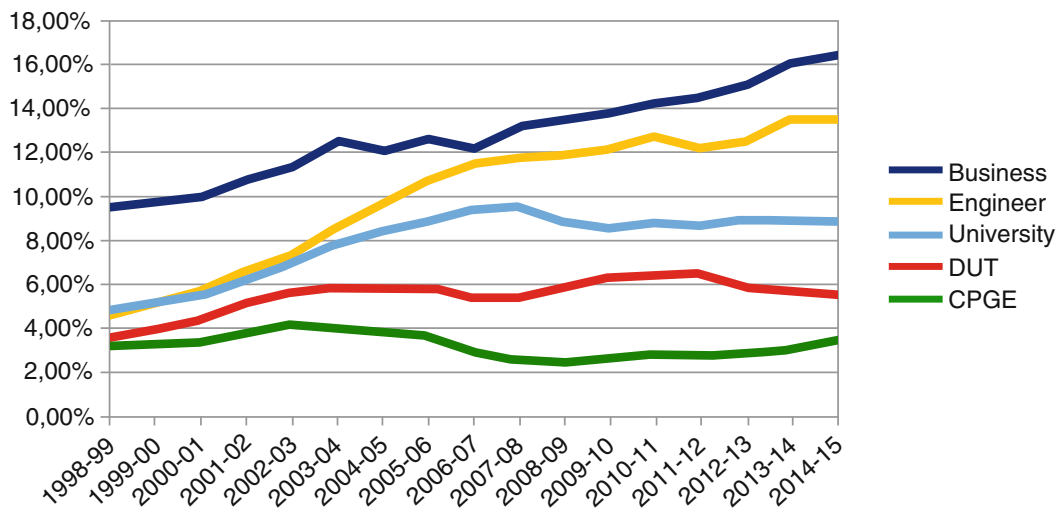

Fig. 6.8 Percentage of foreign students 
Fig. 6.9 Origin of foreign students

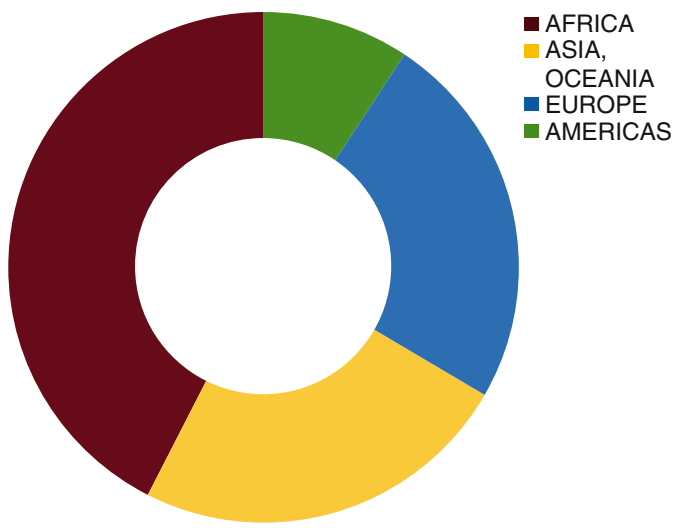

Fig. 6.10 Population and gender repartition in Scientific Preparatory Schools (CPGE) in 2016

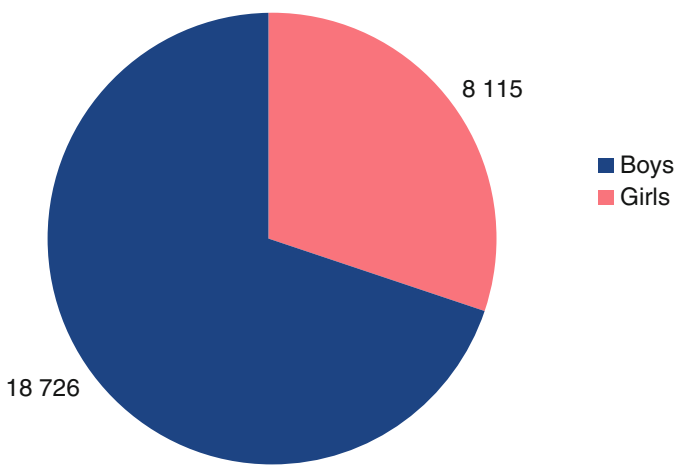

\subsubsection{Preparatory Courses (CPGE and Internal)}

The main entrance scheme to engineering schools (more than $80 \%$ ) is not via university but via preparatory schools. The two first years of the engineering training are preparatory courses, done either in special preparatory schools (CPGE) or already integrated within the school. Around 27,000 students (93\% from scientific, $7 \%$ from technical Baccalaureate) go through CPGE each year; see Fig. 6.10. There are great geographical and demographical disparities: a third of the students studies in Paris and a third are female. Teachers in CPGE, around 86,000 people, belong to the ministry of secondary education, they do not conduct any research and are not affiliated with a university or a higher education institute.

The main networks of engineers schools have their own "students shuffling" system, allowing students to allocate, at the completion of their two first internal preparatory years, according to their accomplishments and desires, especially the Polytech and INSA networks.

At the end of these 2 years, competitive exams, national or local, rank students, in different ranking systems. Different schools unite in consortia and networks, sharing the same examinations, allowing themselves to rank internally students in order for them to express their choices and allocate places according to offer 
and demand. Some of these examinations are incompatible with one another, so students have to choose which schools they want to apply to. The three main public competitive examinations are: Polytechnique-Écoles Normales-ESPCI, CentraleSupélec, Mines-Ponts. These exams are open to students having followed 2 years of preparatory schools, whether at university (a small proportion) or in special training schools (CPGE).

\subsubsection{Technical University Institutes (IUT) and Their Diploma (DUT)}

With a Technical Baccalaureate, students can enter university and become higher technicians in Technical University Institutes (113 IUT in France and one in UCBL), which are limited to 2 years training, eventually followed by a professional license. More than $70 \%$ of them receive a University Diploma in Technology (DUT), an intermediate degree of the LMD system. This diploma allows for immediate employability and about $90 \%$ of the DUT students after graduation do get a permanent position within the first year. But only $10 \%$ of the graduates choose to do so! DUT is somehow "hijacked" by $90 \%$ of students that in fact are looking for further training, and especially as engineers. The French job market lacks skilled technicians (1500 euro/month median first salary): students want to invest in studies in order to get a Master (1900 euro/month median first salary) or an engineer's salary (2700 euro/month median first salary) for the same $90 \%$ students placement success rate. This situation has to be kept in mind when analyzing the French Engineering School system.

\subsubsection{Engineering Schools}

Around 100,000 engineers are being trained in 210 French engineering schools today, leading to 33 thousand graduations a year, a fifth of them in schools included in a university. Unlike the general Bachelor program at university, the entrance to these schools is competitive and the dropout rate is very low.

An engineering school has to be accredited by the Ministry of Higher Education and Research, after an inquiry, every 6 years by a special quality assessment body, the Engineering Accreditation Institution (CTI); this requirement has existed since 1934. Students training, students job placement, recruitment of the personnel, industrial and academic partnerships, and self quality assessment are among the main criteria. CTI belongs to the European Association for Quality Assurance in Higher Education (ENQA) and the European Consortium for Accreditation (ECA).

These schools are often independent and usually do not belong to a university. In particular, engineering school training is limited up to the fifth year after national 


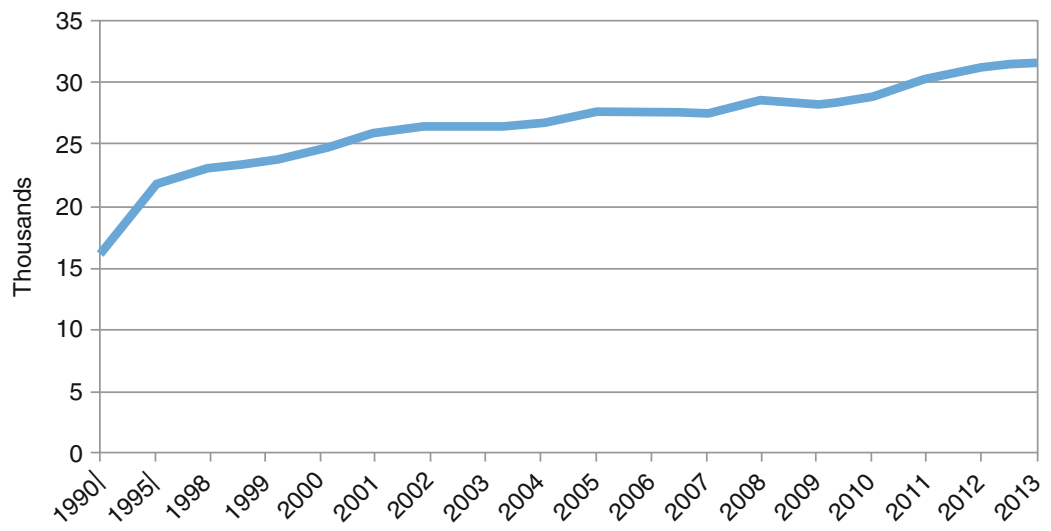

Fig. 6.11 Number of engineering degrees (in thousands)

Baccalaureate Degree or equivalent, that is to say, the equivalent of Master degrees, and these institutions are not permitted to deliver Doctoral diplomas. In order to do so, they have to establish a partnership with a university. A fair amount of their staff usually belongs to a research laboratory hosted by a university. Therefore, compared to partner countries such as Finland or Russia, most universities are "classical" universities, while engineering schools take the role of "technical" universities. Moreover, let us recall that in most of these schools, specialized work begins in the third year, the first two being preparatory years, taught internally or in another institution (CPGE). All in all, engineering degrees represent around two-thirds of all the scientific and technical Masters in France.

The 210 accredited engineering schools in France fall into three main categories. First, there are schools integrated inside a university, Polytech is an example of such schools. Then there are schools with integrated preparatory years, INSA is an example. Then there are schools which train only for 3 years after 2 years of preparatory school (CPGE), École Centrale is an example. We will further describe these paradigmatic examples below. Around a third of the engineering schools are private, for a fourth of engineering students. As shown in Fig. 6.11 the number of engineering degrees awarded each year has been increasing by $3.4 \%$ a year over the last 5 years, reaching 32,800 in 2015 .

Around $4 \%$ of engineering students continue their studies with a $\mathrm{PhD}$. There are around $1 \%$ of the students doing so in private schools and professional Masters, compared with $14 \%$ in research Masters.

The engineering schools are often part of networks such as the Polytech ${ }^{4}$ or the INSA $^{5}$ networks. The Polytech network is constituted of 13 public schools, training more than 68,000 students and leading to 3000 graduations per year. The INSA

\footnotetext{
${ }^{4}$ http://www.polytech-reseau.org/.

${ }^{5}$ http://www.groupe-insa.fr/.
} 
network of six schools trains 2300 engineers per year for 60 years, amounting to more than 80,000 engineers on duty today.

Around 100,000 students are being trained in 210 French engineering schools today, for 33 thousand graduations a year, a fifth of them in schools included in a university. Unlike universities, the entrance to these schools is competitive. Their curricula and diplomas are continuously assessed and validated by the Commission of Engineer Title (CTI). This commission is a member of the European Association for Quality Assurance in Higher Education and belongs to the French Ministry of Higher Education and Research.

The entrance selection scheme is either at the beginning of the first year, right after Baccalaureate graduation, or in the third year. A continuous selection weeds out failing students at the end of each year. The two first years are preparatory courses, done either in special preparatory schools (CPGE) or already integrated within the school.

\subsubsection{Engineer Training in Lyon}

Higher Education players in Lyon are gathered into the Université de Lyon consortium, which comprises 129,000 students and 11,500 researchers; see Fig. 6.12.

Université Claude Bernard Lyon is the science and technology university of the Université de Lyon. There are 3000 researchers for 68 research laboratories and 40,000 students in 13 teaching departments. The mathematics research laboratory is the Institut Camille Jordan (ICJ UMR 5208 CNRS, 200 members). Most of the mathematics teachers from the neighboring Engineers Schools, INSA, École Centrale, Polytech, which are as well researchers, belong to this research institute. Lyon has another smaller research institute in the École Normale Supérieure (UMPA UMR 5669 CNRS, 50 members) hosting much less applied mathematicians and no engineers trainer. CPE researchers belong to the Hubert Curien laboratory.

\subsubsection{Civil Engineering}

Course Description: The course Civil Engineering and Construction is the third year of Mechanics License-Civil Engineering. It is administratively attached to the Department of Mechanics Faculty of Lyon 1.

Training Duration: 2 semesters. Number of hours of training at the University: $600 \mathrm{~h}$. Period of internship: 6 weeks. According to the student profile, specific modules and differentiated lessons are implemented.

Course Overview: The aim of this license is to provide an operational, flexible and scalable framework combining scientific and technological knowledge in the area of Building and Public Works. All major areas of construction are discussed: Drawing, Work Management, Energy, Structures, Soil Mechanics, Topography, Materials, etc. 


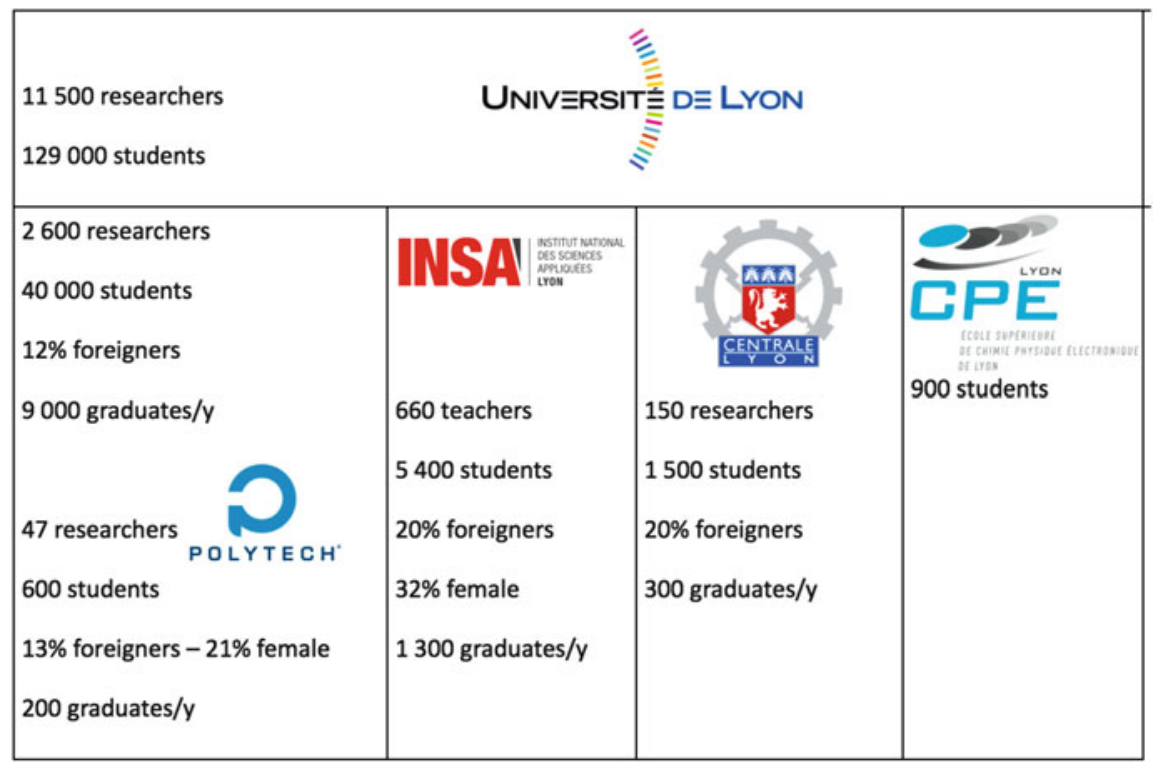

Fig. 6.12 Université de Lyon Consortium

\subsubsection{Master Program}

Courses offered at the Master's degree level satisfy a dual objective of preparing students for research and providing courses leading to high level professional integration. The Master's degree is awarded after acquisition of 120 credits after the "license" (Bachelor's degree) on the basis of training organized in four semesters. The first 60 credits (M1) can, by request of the student, receive an intermediate level national "maitrise" diploma, a heritage of the previous French HE system. The remaining credits lead to the awarding of the national "Master" diploma.

\subsubsection{Polytech}

UCBL hosts the engineers school Polytech. It belongs to a network of 13 engineering schools embedded into universities. It represents a pretty new trend in France, the school in Lyon was founded in 1992 and joined the Polytech network in 2009. It grew to become quite an alternative to more classical engineering schools. The recruitment of Baccalaureate students (aged around 18) is done at a national level through a common procedure, shared with other 29 engineering schools: the Geipi Polytech competitive exam awarding more than 3000 students a ranking into the affiliated schools from which to make a choice. Polytech Lyon majors are chosen by around 200 of them per year (Fig. 6.13). 


\section{Over 14000 students}

\section{Majors grouped in 5 big scientifc areas}

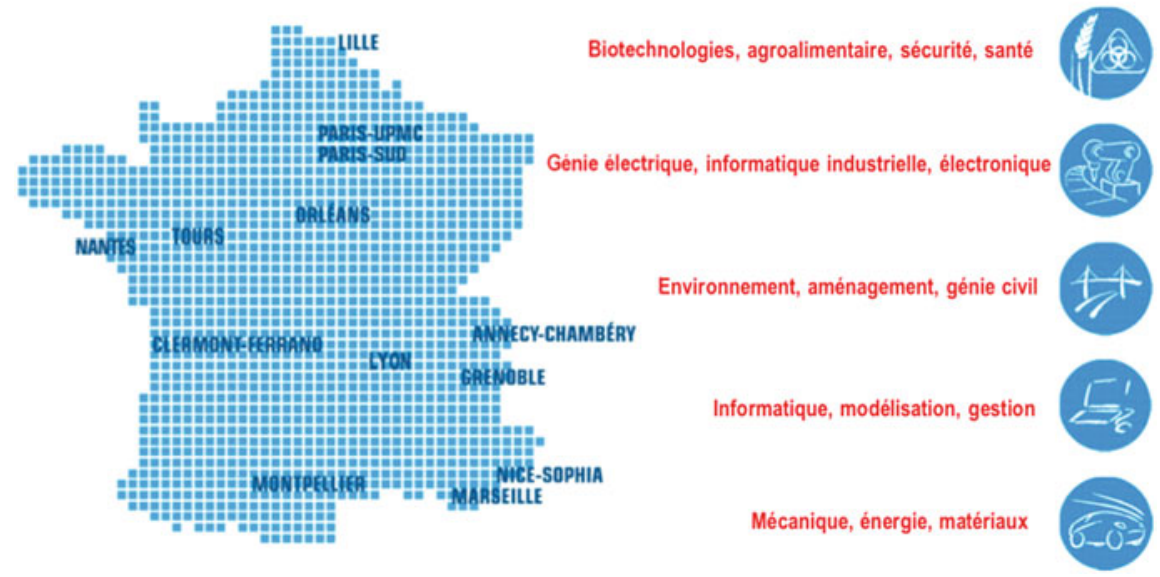

Fig. 6.13 The network of Polytech universities

The two first years are preparatory, following the program of other classical preparatory schools but at the university. The actual choice of the engineer school is done at the completion of these 2 years. A reshuffling of the students, according to their choice of major topic and achievements, is performed inside the Polytech network. A student having begun studying in Lyon might very well end up finishing her/his studies in Polytech Grenoble, for example, because she/he grew interested in the Geotechnic major prepared there. But majors in Lyon are attractive so the reverse is the case: from 120 preparatory students, numbers jump to around 200 in the third year (L3) when majors begin. These majors are selective and it fuels the competition between students at a national level in the network. The sex ratio is around $20 \%$ of girls, but a great effort is being made in that respect, the preparatory school ratio being now about $30 \%$.

There are six majors in Polytech Lyon, rooted in the scientific workforce in UCBL:

- Biomedical engineering;

- Computer science;

- Materials sciences;

- Modeling and applied mathematics;

- Mechanical engineering;

- Industrial engineering and robotics.

Every student from the third year on belongs to one of them. These majors are backed up by research laboratories of the UCBL to which the teachers belong as researchers. Most of these laboratories are associated with CNRS (French National 
Agency for Research). For mathematics, it is the Institut Camille Jordan UMR CNRS 5208 (ICJ). Two 6-month internships in industry or research laboratory are performed in the fourth and fifth year of study. International training is mandatory, whether as a student or as an intern.

\subsubsection{INSA}

The seven National Institutes for Applied Sciences (INSA) form the largest network of engineer schools in France, amounting to 12\% (10,200 students) of all the trained French engineers. The first institute was open in Lyon in 1957 and had a special emphasis on social opportunities, humanities and international cooperation: special cycles prepare engineer students in the spirit of cultural openness and bilingualism such as EURINSA, ASINSA, AMERINSA, NORGINSA, SCAN, respectively, for European, Asian, South-American, Nordic and English speaking students. French students and foreign students are mixed half and half. Each learns the language of the other group during the two first preparatory years, followed by a 1 month industrial internship in the alien culture. The cultural and ethical dimensions of science and technology, and their teaching, are therefore a distinctive point of these institutes. Just as in the case of Polytech, the two first years are preparatory and students can or may have to move from one INSA to another, at the end of the second year, in order to find a major adapted to their achievements and desires. The INSA in Lyon counts among its 5400 students over 5 years of training, 20\% of foreign students, $32 \%$ of female students and $31 \%$ of grant students, which is a distinctive mark of its social openness, compared to other more socially discriminative schools. Among its 660 teachers, more than half are researchers as well and depend on a laboratory. In mathematics, among the 45 members of the math Pole, 13 belong to ICJ, and another 15 to other laboratories (computer science, acoustics, energy, civil engineering).

There are 12 majors taught in Lyon, linked to research laboratories. They begin in the third year:

- Biochemistry and Biotechnologies

- Bio-computer Sciences and Modeling

- Civil Engineering and Urbanism

- Electrical Engineering

- Energetic and Environmental Engineering

- Mechanic Conception Engineering

- Mechanic Development Engineering

- Plastic Process Mechanic Engineering

- Industrial Engineering

- Computer Science

- Material Sciences Engineering

- Telecommunications 


\subsubsection{5 École Centrale de Lyon}

This engineer school was founded in 1857 and belongs to the "Centrale group" of eight schools, five of which are in France, others in Beijing (China), Casablanca (Morocco) and Mahindra (India). This network selects students after 2 years of preparatory school. Teaching therefore only lasts 3 years. The national competitive exam, common to 10 schools (the five French Centrale and five other schools) is called Concours Centrale-Supélec, is one of the three top competitive exams in France with Polytechnique-ÉNS-ESPCI and Mines-Ponts. The best students in French preparatory schools take these three selection exams. There are around 1000 students in this 3-year school, completed with around 100 Master students and 200 $\mathrm{PhD}$ and post-doctoral students. Half of the 200 teachers are as well researchers. The 3 years of study are divided into 2 years of common core followed by seven majors lasting for one semester:

- Civil Engineering and Environment;

- Mathematics and Decision;

- Aeronautics;

- Transportation and Traffic;

- Computer Science and Communication;

- Energy;

- Micro- and Nano-biotechnologies.

The study is structured around three main collaborative projects, one each year, of 9 months in the first 2 years and of 6 months in the third year. Internships punctuate the education as well, of increasing complexity, from an execution internship of 1 month in the first year, application of 3-4 months in the second year, to the study internship of 6 months in the third year. Sabbatical leave during the school is promoted, for personal projects, such as industrial internship or academic study abroad or professionally oriented projects. Once graduated, students can continue their study with complementary Masters such as innovative design, management or numerical methods in mathematics, with jointly accredited diplomas such as "Maths in Action: from concept to innovation". A fair proportion of students go on with $\mathrm{PhD}$ studies, whether within one of the six research laboratories present inside the school, or in a joint research laboratory where most of the teachers perform their research. In mathematics, all researchers (8) belong to the ICJ laboratory.

\subsubsection{Curriculum Details}

The two first preparatory years in UCBL are representative of the amount of mathematics followed by students. We chose to detail the Electrical Engineering stream in INSA Lyon. 


\section{S1:}

Algebra 1: Foundations of logic, ensembles, maps, arithmetics, complex numbers, $\mathbb{R}^{2}$.

Calculus 1: Reals, real functions, sequences, limits, derivation, minimization, maximization, inf, sup, derivation of an implicit function, higher order derivation, convexity, l'Hôpital law, differential equations of first order, primitive.

\section{S2:}

Algebra 2: Linear algebra, polynomials, rational fractions, vector spaces of finite and countable dim, linear applications, matrices, determinant.

Calculus 2: Integration and approximation, change of variable, simple elements, circular and hyperbolic formulas, differential equations of second order, indefinite integrals, applications in probability and statistics, Landau notation, limits, Taylor polynomials and series, Taylor-Lagrange remainder.

\section{S3:}

Algebra 3: Diagonalization, groups, determinants, eigenspaces, spectral decompositions, Cayley-Hamilton, powers, exponential of a matrix.

Calculus 3: Several variables functions, differential calculus, applications, convexity, Lagrange multipliers, implicit functions, Euler equations, isoperimetric problems.

\section{S4:}

Algebra 4: Geometric algebra, bilinear forms, scalar products, rank, kernel, Gauss orthogonalization, adjoint, spectral decomposition of self-adjoint operators, quadratic forms, Sylvester theorem, affine geometry, conics, quadrics, $\mathrm{O}(\mathrm{p}, \mathrm{q})$.

Calculus 4: Series and sequences, Cauchy, d'Alembert, uniform convergence, Abel theorem, trigonometric and Fourier series, entire series, integrals depending on a parameter, differentiation and continuity, eulerian functions, Laplace transform, applications to differential equations, geometry and differential calculus, curves and surfaces, geometry, parametric curves, curvature, Frenet frame, tangent and normal spaces, vector spaces, differentials, line, surface and multi-dimensional integrals, Stokes theorem, Green formula.

Applied algebra: Gröbner basis, Perron-Frobenius theorem and web indexation.

Student project.

\section{S5:}

Algebra 5: Groups and morphisms, Lagrange theorem, cyclic groups, morphism, image, kernel, Euler index, $\mathrm{Z} / \mathrm{nZ}$ ring, prime numbers, quotient groups, dihedral groups, group action, orbits, stabilizer, Bernside, Sylow theorems, SO_3 subgroups, Platonian solids.

Numerical analysis: Linear algebra, Gauss method, iterative methods, conditioning, spectral problems, power method. Nonlinear equations, Newton, secant method, remainder estimation. Interpolation, approximation, polynomial interpolation, mean squared, numerical integration, discrete Fourier transform, Cooley-Tuckey fast Fourier transform, differential equations, Cauchy problem numerical solution, Euler method, Runge-Kutta, implicit and explicit methods.

Topology: Metric space, normed space, topological space, continuity, Baire lemma, Banach fixed point, Bolzano-Weierstrass theorem, Ascoli theorem, Stone- 
Weierstrass theorem, Lebesgue integral, Riemann vs. Lebesgue, Lebesgue dominated convergence theorem, Fubini theorem, Lebesgue measure on $\mathbb{R}^{n}$, random variables, measures.

Starting with the third year, the curriculum depends on which program we are talking about: INSA, Polytech, CPE, Centrale Lyon. We chose to detail here the Electrical Engineering program of INSA. The amount of mathematics is decreasing with time; most of the technical prerequisites are put in the first year of major study:

S6: $96+88=184 \mathrm{~h}$ of math for 8 ECTS. Hilbert spaces, Fourier series, distributions, interpolation, approximation, numerical integration, solving linear systems. Fourier, Laplace, Z-transforms, ODEs, linear systems, convolution, difference equations using Matlab.

S7: $83 \mathrm{~h}$ for 4 ECTS. Complex analysis, PDE, probabilities. Numerical Analysis: Non linear equations, PDEs Using Matlab.

S8: $60 \mathrm{~h}$ 3ECTS. Probability and statistics, conditional probabilities, statistics, moments, central limit theorem, estimation, hypothesis tests, regressions, experimentation plans.

From then on, mathematics is only used as a tool integrated in other teaching units.

The peculiar fact about the preparatory school in UCBL is that, unlike most other preparatory schools, it is organized by units that delivers ECTS: Each semester weights 30 ECTS which come from five teaching units of 6 ECTS. The two first years of the curriculum are followed by all students going to engineer schools at UCBL, but there are some other non-math options shaping them in three different groups: physics and math, computer science and math, and mechanics and math. ${ }^{6}$

Open Access This chapter is licensed under the terms of the Creative Commons Attribution 4.0 International License (http://creativecommons.org/licenses/by/4.0/), which permits use, sharing, adaptation, distribution and reproduction in any medium or format, as long as you give appropriate credit to the original author(s) and the source, provide a link to the Creative Commons license and indicate if changes were made.

The images or other third party material in this chapter are included in the chapter's Creative Commons license, unless indicated otherwise in a credit line to the material. If material is not included in the chapter's Creative Commons license and your intended use is not permitted by statutory regulation or exceeds the permitted use, you will need to obtain permission directly from the copyright holder.

\footnotetext{
${ }^{6}$ More details can be found (in French) on http://licence-math.univ-lyon1.fr/doku.php?id= mathgeneappli\#premiere_annee_du_parcours; see also http://licence-math.univ-lyon1.fr/doku. php?id=mathgenappliprog. The details for INSA can be found at the following URL: http://www. insa-lyon.fr/formation/offre-de-formation $2 / \mathrm{g} / \mathrm{d} /$ ?gr=ING.
} 